\title{
Communication as an Educational Skill in School Units of the 21st Century: A Survey Research
}

\author{
Evangelia Raptou ${ }^{1}$, Panagiotis J. Stamatis ${ }^{2} \&$ Nikolaos Raptis ${ }^{1}$ \\ ${ }^{1}$ University of the Aegean, Rhodes, Greece \\ ${ }^{2}$ Dpt. of Sciences of Preschool Education and Educational Design, University of the Aegean, Rhodes, Greece \\ Correspondence: Panagiotis J. Stamatis, Assistant Professor, Dpt. of Sciences of Preschool Education and \\ Educational Design, University of the Aegean, Rhodes, Greece.
}

Received: April 10, 2017

Accepted: May 10, 2017

Online Published: May 26, 2017

doi:10.20849/aes.v2i2.153

URL: https://doi.org/10.20849/aes.v2i2.153

\begin{abstract}
Awareness about values of communication skills and the necessity for their cultivation brought them into foreground of educational field. Thus, they are qualified as a basic framework for the creation of modern democratic, intercultural and open schools to the world. Communication is recognized as a basic social skill by the program P21 Framework for the 21st Century Learning and by thousands of teachers and hundreds of schools in the US and many other countries. Since communication skills are related to many aspects of modern Greek educational situation, such as teaching, school administration, evaluation and development of good interpersonal relationships, the main purpose of this paper is the presentation of a survey research about communicative behavior of secondary education teachers and school heads, the depiction and enhancement of their communication style and the assessment of their views in regards to importance of communication skills in carrying out their professional role. Results of the research showed that teachers recognize to themselves very good communication skills, including advocate active listening, collaboration development ability and empathy.
\end{abstract}

Keywords: communication, social skills, communication competence, P21, education, school leadership, school management

\section{Introduction}

Discussion about the concepts of "communication" and "education" contributes to the enhancement of the timeliness and importance of communication skills within democratic and creative schools of the 21st century. The systemic view of an educational organization (Stamatis, 2012, 2015. Pasiardis, 2004. Willke, 1997), the assessment of its behavior as a result of ongoing interactions indoor and outside; and the theory of triple-dependent its critical of the functions of feedback, balance and adaptation make dealing with educational issues interwoven with the communication role of each participant, either individually or collectively and communication skills in order, ultimately, to speak one for absolute correlation and dependence of educational quality on the level of personal communication skills (Saitis, 2014, 2008a, b, 2007. Katsaros, 2008. Raptis \& Vitsilaki, 2007).

The achievement of specific educational goals requires cooperation. The cooperation requires the coordinated examination of existing interactions, keeping in mind that coordination is an achievement of those people who know how to communicate in a group without dropping or affected the value of the participating members, but praising their personal contribution to the production of satisfactory results. Such positions operating like evaluation components for the importance of communication skills that teachers and school managers must have for the production of valuable educational work, as well as various aspects of modern Greek educational situation, such as teaching, administrative work, assessment and development of interpersonal relationships are perfectly connected to communication capacity of the involved persons in school environment matters. While most researches focused on various leadership models or educational behavior, only a limited number of studies which have directly targeted the communications capacity saw the light of day.

In a global level however, a strong interest in the importance of the effectiveness of communication practices within an organization and an educational institution is particularly observed (Bush, 2011. Gorton \& Alston, 2010, 2008. OECD, 2008). Communication is internationally recognized as a basic teaching skill and as a 
necessary leadership capacity of the primary and secondary school heads in order they are able to succeed in their difficult and complicated daily duties (Stamatis, 2013). Taking that for granted, school heads have the duty -on the one hand- to improve their communication practices and at the same time -on the other hand- to adopt more communicative roles. They have to manage diversity, which may be related to gender, race, native language speakers, local or national culture, physical impairments, age, social class etc. It is also important school heads to overcome any communication barrier, to develop active listening and feedback skills, to be familiar with possibilities that provide information technology (Everard \& Morris, 1999). Furthermore, it is necessary school heads understand that in addition to their role as communicators, they have more equally important communicative roles, such as receivers of messages, supervisors and the facilitators of communication (Gordon \& Alston, 2009).

Communication, therefore, is not only a medium but also a fundamental aim of modern and globalized educational policy since the New School, the school of the 21st century, envisions people to be able to think critically and communicate effectively, people who would be able to solve problems and develop collaborations in many ways under difficult and various circumstances (Reimers \& Chung, 2016). Under this educational prospect, the program P21 Framework for the 21st Century Learning which was developed with teachers' contribution, by experts in education and leaders stem from business environment, it is systematically implemented in hundreds of schools inside and outside the US where communication is greatly considered as a critical social skill (Alhashmi \& Ghadimi, 2013. Soulé, Bates, \& Whitsett, 2013. AMA, 2012. Dede, 2009).

All the above mentioned, as a theoretical framework, were stimulating to dealing with this research and effort to bring up to the surface daily communicative practices related to secondary education Greek teachers and secondary school heads. The communicative behavior of that school heads and teachers, as a key component for social skills development in relation to P21 Framework for the 21st Century Learning program is considered to be an added innovative intervention and one of the most fundamental key functions of educational administration and instructional communication as well.

\section{Method}

Every research aims in providing satisfactory answers in three basic questions: what, why and how? What is the content of the subject it studies, why does it attract the interest and how it would be methodologically and procedurally investigated? As in usual practice, quantitative methods as the one applied in present research. They were applied in order hypotheses to be examined about investigating social phenomenon, which is stable during research implementation. By interpretation of the confirmed results hypotheses are rejected or amended. Quantitative research allows the ensuring of a relatively large sample which can be put under statistical analysis and the study of a phenomenon on a large scale with a prospect to a possible generalization of results (Fokiali \& Raptis, 2008). It was the main reason of present research methodological choices, the components of which are presented below in more details.

\subsection{Purposes of the Study and Research Questions}

The aim of present research is the investigation of communicative behavior, the evaluation and assessment of communication skills of Greek teachers and school heads of Secondary Education (SE), as it comes out from the statements in specific self-assessment test mentioned below. To be more specific, it was attempted to be investigated the views of participants (SE teachers and school heads) in relation to the way they perceive themselves in regards to their communication style, what communication skills or attributes they believe that they have and in what level they recognize them in relation to themselves, in order to be able later the assessment degree of each of them communication skills according to their own view about their own communication competence. Such kind of assessment positively contributes in increase of the interest of educational practitioners of the 21 st century about their teaching, administrative and/or leadership profile.

More specifically, the following five groups of research questions were set. Each group was corresponded to one of the main research purposes which are depicted as follow:

1. Are views of SE teachers and school heads differentiated in relation to demographics - personal characteristics (gender, age, years of work, experience at the same school unit, school level, teaching position, managerial experience and studies)?

2. Does the degree of self-esteem of SE's teachers and school heads differ regarding their communication skills?

3. Does perception of SE teachers and school heads differ in comparison to their communicative behavior with other school community members (colleagues, students, parents)? 
4. What is the dominant communication style which SE teachers and school heads believe / perceive they have? Is this style appropriate for teaching practitioners of the 21 st century?

5. Do SE teachers and school heads believe that their communication skills / abilities contribute in a positive way to development of good and effective relationships to those who are communicating with into the school environment?

\subsection{Data Collection Instrument}

The subjects of this study, the literature review and clarification of the purposes have determined the choice of research data collection instrument which is a special questionnaire. So, for the data collection of this study the diagnostic tool of J. M. Wiemann (1977) "Communication Competence Scale (CCS)" (Note 1) was used. Actually, it is a valid and reliable self-report test which has been used in a significant number of studies internationally contacted. It was created to investigate the way people communicate each other, not only in a specific communicative situation but also in the most of social situations. The CCS proposes a fivefold model of communication skills competence: interaction management, empathy, affiliation/support, behavioral flexibility and social relaxation. Among them, the most clearly recognized components of communicative competence are empathy, behavioral flexibility and interaction management. These are components of the communication competence in which interaction is managed in a central role. The initial results of CCS implementation by J. M. Wiemann (Note 2) (1977) revealed a strong, positive and linear relationship between the management of interaction and communication skills. Additionally in present research, the CCS was accompanied by a questionnaire, which was exclusively constructed for the needs of the study aiming in gathering information about demographics of the participating teachers, focusing on gender, age, possession in SE school unit and their studies.

In twenty one (21) of the twenty three (23) school units where questionnaires were distributed, a personal visit of the research team had taken place. In two (2) rest school units questionnaires were shared through colleagues in confirming the theoretical principle that colleagues and friends can persuade and assist (Bell, 1999). Every questionnaire was accompanied by a letter explaining the purpose of the research. Furthermore, the letter was guaranteed the anonymity of the participants. At the same time, there was a contact with SE school heads, in order personal acquaintance to be ensured and finally, a call phone thanksgiving communication dictated for courtesy and genuine gratitude reasons, because even though the completion of a short questionnaire is not very difficult, it is at least a kind of harassment and deprivation of personal time.

\subsection{Sample of the Research}

In present study which conducted in October and November 2016, a total amount of two hundred (200) SE school unit staff were involved (teachers and school heads). All of them taught in SE school units of Larisa prefecture (central Greek territory), in middle schools (gymnasium), and in general high school (lyceum), in vocational high school and in special vocational high school. One hundred and seventy (170) SE school teachers of them, were instructors of various specialties, twenty five (25) of them were school heads and five (5) of them were deputy school heads. The SE school units were been chosen in random. It was provided teachers and school heads to be equally interviewed within high school units of Larisa prefecture. So, questionnaires were distributed to provinces of Elassona, Tyrnavos, Agia and the city of Larisa. In particular, questionnaires were distributed in ten (10) middle schools, eight (8) high schools, two (2) middle schools with upper secondary classes, one (1) music school, one (1) vocational school and one (1) special need professional middle school. In total, twenty three (23) school units were participated in present study and two hundred (200) persons. The aforementioned constitute the sample of the research.

\section{Results}

For the extraction and classification of results into tables the Statistical Package for Social Sciences software (SPSS) v.20 was used. By the research team were conducted the coding of answers provided by participants in the study and completed the introduction of coded answers in SPSS. Variables were either dependent or independent. The dependent variables were identical to those of the questionnaire statements. The independent variables were related to the gender, age, years of educational experience, type of school in which were teaching the participants, the amount of teaching staff in school unit, position (post) held in school unit, the experience in a head position and studies.

Initially, the data were analyzed in order the demographic characteristics of the sample to be described. Since the purpose of the research was to investigate the communication behavior of SE school heads and teachers, the analysis of demographics initially aimed to show if the sample was proportional to the total population of SE in 
Larisa prefecture or not and secondly, to leak out the results in en equal way to demographic elements, as they were related to independent variables of the research. Results of analysis were described after their classification in two main categories. The first category relates to descriptive statistics and descriptive results analysis. In this type of analysis one can see only the data percentages of participants in the sample of research and their characteristics in relation to the gender, age, position in SE school unit and studies (Tables 1, 2, 3, 4). The second category relates to inferential statistics and depiction of inductive results. With inferential statistics researchers tried to reach conclusions that extend beyond the immediate data (Table 5). Actually, they used inferential statistics to make inferences from research's data to more general conditions since descriptive statistics simply to describe what's going on with data related to the sample.

\subsection{Descriptive Statistics}

Table 1. Gender-related frequencies

\begin{tabular}{cccccc}
\hline & Gender & Frequency & Percent & Valid Percent & Cumulative Percent \\
\hline Valid & Men & 76 & 38,0 & 38,0 & 38,0 \\
& Women & 124 & 62,0 & 62,0 & 100,0 \\
& Total & 186 & 100,0 & 100,0 & \\
\hline
\end{tabular}

Table 2. Age-related frequencies

\begin{tabular}{llcccc}
\hline \multicolumn{1}{c}{ Age } & Frequency & Percent & Valid Percent & Cumulative Percent \\
\hline Valid & Up to 40 years & 20 & 10,0 & 10,1 & 10,1 \\
& From 41-50 years & 103 & 51,5 & 51,8 & 61,8 \\
& Over 50 years & 76 & 38,0 & 38,2 & 100,0 \\
Total & 199 & 99,5 & 100,0 & \\
Missing System & 1 & 0,5 & & \\
& Total & 200 & 100,0 & & \\
\hline
\end{tabular}

Table 3. Possession-related frequencies

\begin{tabular}{llcccc}
\hline \multicolumn{1}{c}{ Position in SE school unit } & Frequency & Percent & Valid Percent & Cumulative Percent \\
\hline Valid & Teachers & 170 & 85,0 & 85,0 & 85,0 \\
& School Heads & 25 & 12,5 & 12,5 & 97,5 \\
& Deputy school heads & 5 & 2,5 & 2,5 & 100,0 \\
& Total & 200 & 100,0 & 100,0 & \\
\hline
\end{tabular}

Table 4. Study-related frequencies

\begin{tabular}{llcccc}
\hline \multicolumn{1}{c}{ Studies } & Frequency & Percent & Valid Percent & Cumulative Percent \\
\hline Valid & BA1 & 145 & 72,5 & 72,5 & 72,5 \\
& BA2 & 16 & 8,0 & 8,0 & 80,5 \\
& MA / MSc / MEd & 34 & 17,0 & 17,0 & 97,5 \\
PhD & 5 & 2,5 & 2,5 & 100,0 \\
Total & 200 & 100,0 & 100,0 & \\
\hline
\end{tabular}




\subsection{Inferential Statistics}

Trying to investigate whether gender influences the communication behavior of teachers or not, it was found out that -despite one exemption- there is no other statement/answer with statistically significant difference. Furthermore, it seems that men's communication skill does not differ than women's at all.

Regarding the age, except of two cases in which there is a statistically significant difference, and it holds that (a) teachers with age up to 40 years old understand in a better way all the others and (b) teachers with age over 50 years old say -more than the others do so- the "right things" the "right time". Regarding to all other statements /answers it comes out that views of teachers do not vary according to their age.

In relation with independent variable of position (post) in $\boldsymbol{S E}$ school unit, it was found out that within twenty seven (27) of thirty six (36) statements/answers there is no statistically significant difference (ns $=0$ ). This finding could be interpreted that the position one holds in a SE school unit does not affect communication behavior. On the opposite, in the rest nine (9) cases stated that there is a statistical significant difference which means that the position someone holds in a SE school unit could affect its communicative behavior.

In regards to independent variable of studies, only in two (2) cases it was found a statistically significant difference and it seems that: (a) teachers holding a $\mathrm{PhD}$ are less calm when they are talking; and (b) teachers holding just the basic study degree (BA) seems they better communicate compared to those who holds any other study degree. In all other cases, it comes out that views of participated teachers do not differ regarding the training and qualifications they have.

In table 5 are shown the central tendency indicators and measures of variability of research data in order a description and interpretation of research tool to be done by the research team. Using the measures of central tendency (Mode, Median, Mean) and measures of variability (Range, Standard Deviation) it is possible a complete overview of basic characteristics of the sample to be given in relation to its characteristics regarding their communication skills.

Table 5. Indices of central tendency and dispersion measures of the statements of the sample subjects

\begin{tabular}{lccccccc}
\hline \multicolumn{1}{c}{ Research Groups } & $\begin{array}{c}\text { Mini } \\
\text { mum }\end{array}$ & $\begin{array}{c}\text { Maxi } \\
\text { mum }\end{array}$ & Mean & $\begin{array}{c}\text { Standard } \\
\text { Deviation }\end{array}$ & Mode & Median & Range \\
\hline Teachers & 117 & 182 & 151,04 & 11,384 & 145 & 151,00 & 65 \\
\hline School heads & 134 & 177 & 155,16 & 10,734 & 142 & 158,00 & 43 \\
\hline Deputy school heads & 152 & 162 & 157,20 & 3,701 & 152 & 157,00 & 10 \\
\hline Total & 117 & 182 & 151,71 & 11,233 & 145 & 151,00 & 65 \\
\hline
\end{tabular}

What observed on Table 5 is that representation of teachers' mean is up to 151,04 , it is up to 155,16 in school heads and up to 157,20 in deputy school heads. As the sample of deputy school heads is very small -only five (5) individuals- are considered to be less reliable of all school staff categories. The median of school heads is the higher in those three categories. The same is observed in mode, where in case of school heads it is shown the higher value comparing to the amount of all participants. The difference between the smallest and largest value, the range, in the case of school heads is lower than teachers. Therefore, communication skills seem to be more developed among school heads and deputy school heads comparing to teachers. However, according to interpretation given by research team, all participants in this study were indicated to gather more than 108 grades in CCS each and thus teachers seem to have very good communication skills according to their self-assessment.

\section{Discussion}

Among many others, distribution and gathering of research questionnaires required some communication skills on behalf of the research team members to be disclosed in order participants be convinced in voluntarily participating and providing trustful answers in given questions. The response to this requirement was one of the most difficult points of present research, related to the theoretical and practical level as well. In fact, the "protocol of research good manners" was required communication relationships to be developed within researchers and participants in the beginning and at the end of research procedures. Initially, it was tried to be achieved through personal supplication, in order participants provide answers to the questionnaire and then -at the ending of research procedures - to be smoothly closed the cycle of any communication relationships between 
participants and researchers. Moreover, the pressure of time and distance between school units were two added binding and negative parameters which contributed to increasing of difficulty degree of this research. In spite all difficulties, the research team of conducting this study based on successful implementation of the P21 Framework for the 21st Century Learning Program in USA and in many other countries, focused on communication as a basic educational skill of present century school units and not only as a social skill. This program consists a challenge for further research on this matter as communication is considered to be the milestone of good school practices development, fundamental for improving the educational and administrational processes and a positive prospect for professional development of teachers.

Based on successful implementation of P21 in USA, the main purpose of this research was actually the study of communicative behavior of teachers and heads/deputy heads of secondary education school units and the assessment of their views about the importance of communication skills they have during the fulfillment of their professional and educational role. The choice of J. M. Wiemann (1977) questionnaire was consistent with the theoretical framework of this survey research, as it was created to study the communicative behavior of people in various communicative situations, focusing on five communication skills which had been named «managing interaction, empathy, support, behavioral flexibility and social relaxation» (Wiemann, 1977:195). As various aspects of modern Greek educational situation, such as teaching, school administration, assessment and interpersonal relationships development are absolutely associated with communication skills and as the interest for the effectiveness of communication practices in educational process is worldwide; it makes communication competence a basic requirement for effective teaching and improving leadership capabilities especially for secondary school heads, very useful for their administrative and educational planning effectiveness.

Finally, the fact that most research focused on various leadership models or educational behavior, without being focused on communication skills of teachers up to now, it underlines the need for systematic engagement to research issues related to communicative behaviors in school environment, aiming in improvement of educational goals (Fullan, 2017. Harris \& Jones 2016. Harris, 2014).

It is estimated that present research would be able whether become the trigger for more engagement with communication skills of teachers and school heads working in Greek educational system -this is actually a basic aspect of educational communication skills- or to provide more educational aspects of deepening the study and creating innovative programs for more effective teaching and addressing conflicts among those who are involved in educational settings and solving of various problems in a sense of collaborative attitude. Furthermore, the research on this subject would be able to "convince" university departments in establishing sectors related to effective communication as teaching strategy, as conflict management process and structural element of leadership and administration in education.

In addition, it is a need the teachers' training programs to show priority in development of communication skills both for those who are already working in education and even more for new appointed teachers as they have not sufficient knowledge of appropriate communication behavior in school unit, basically due to lack of their experience and studies. It is a great duty of any state to educate teachers and school heads in communication matters in order to support their complicated and multi task job in fields of education. Also, it is a great duty to legislate objective evaluation criteria for choosing the appropriate staff in managerial positions. Those criteria must give priority in communication skills of which must hold all who have the intention to become heads in an organization, as a minimum of requirements for everybody and especially to those who are going to become school heads.

The above mentioned suggestions are not intended to meet an arrogant advisory disposal, but only to provide a prospect on issues of communication in education. Albeit it is considered to be taken for granted or given, nobody should forgets that official focus on those issues has recently happened even in countries where already have experienced an economic and technological development for many years. Those experiences allow countries to design and develop a variety of experiments in the framework of educational innovations, as it has happened with the Program P21 Framework for the 21st Century Learning which is the background for conducting this research.

\section{Concluding Statements}

The juxtaposition of the research findings is based on the axis of demographic characteristics of the sample and on the axis of research objectives and relevant research questions. Regarding to the demographic characteristics presented in the first part of the results, it could be summarized by reiterating the following that: 
- The sample of the research was consisted by two hundred (200) educators of which one hundred seventy (170) were teachers, twenty five (25) of them were held head positions and five (5) of them were held deputy head positions.

- The numerical primacy of women teachers of the sample is equal to the existing one in Greek educational positions, with a ratio of $2: 1$.

- The majority of appointed teachers was aged more than forty years old.

- The analysis of the sample in regards to years of educational experience shows that majority of participants is escalating among twenty one (21) and thirty (30) years.

- The majority of participants is employed at the same school unit from for six (6) to fifteen (15) years.

- The main sample of participants stems from secondary middle schools (gymnasiums) and secondary high schools (lyceums).

- In the most of school units the number of appointed teachers is escalating among twenty five (25) and thirty four (34) persons.

- Almost the half of participating school heads hold their position up to two (2) years and the rest of them for more than two (2) years.

- The majority of participating teachers (72.5\%) holds only a basic degree (BA).

In regards to purposes of the research the following concluding statements could be reached in spite of any exceptions and in line with research questions:

1st research question: In general, among the views of teachers and school heads there is no differentiation about communication skills in relation to variables of gender, age, position in school unit and studies. To be more specific:

- Communication skills among women and men teachers are not differentiated.

- The views of teachers about the importance of communication skills - which are usually recognized for themselves - are not differentiated due to their age.

- The position a teacher holds in school unit does not significantly affect him/her communication behavior.

- The views of teachers are not differentiated despite their studies and other qualifications.

2nd research question: Communication skills are more developed in school heads and deputy school heads than other teachers. Therefore, the degree of self-esteem among teachers and heads of secondary school units in regards to their communication skills is differentiated.

$3 r d$ research question: All participating teachers in the sample of this research believe that they have very good communication skills and thus, they are competent communicators.

4th research question: Interpreting the main statements noted in provided answers it was found a democratic-humanitarian communication style among all teachers. This style is connected to respect shown in senders and receivers in a communication process. This style is distinguished by the following communication skills: emotional intelligence, positive relationship development ability with others, friendliness, kindness, active listening, collaborative ability, ability to create harmonic relationships, understanding to the problems that others have (empathy). This style is considered to be very appropriate for teaching practitioners of the 21 st century.

5th research question: Both SE teachers, school heads and deputy school heads believe that their communication skills contribute in a positive way to development of good and effective relationships to those who are in communication with them at school environment. All teachers highlight the positive role of communication skills in cultivation of a collaborative atmosphere and development of good and effective relationships to those who are communication seekers in the school unit.

Entire human life is full of "communicative acts". People collaborate, negotiate, persuade, speak, influence or argue each other. The ability of problem solving, the development of critical thinking, professional morality, flexible mobility, collective and collaborative behavior, these are all elements of communication which is the prime social skill. Communication is a leading skill for human creativity and the basic reason of human productivity development. Through communicative behavior humans achieved in becoming fellows each other in the framework of their socialization process - and finally they achieved discuss about human rights and strive with confidence for them. As Plato mentioned 2500 years ago (Plato: Gorgias, LXIII, 507, 47), "To those whom cannot communicate with others friendship never be with them". This means that friendship always goes with 
communication because communication creates friendly relationships and even more than that do its multidimensional social role. Moreover, communication is a fundamental educational skill for schools and people of the 21st century, the century of interpersonal communication and communications growth through many devices and applications.

\section{References}

Alhashmi, S., \& Ghadimi, M. (2013). The Partnership for 21st Century Skills. A-801 - Education Policy Analysis and Research Utilization in Comparative Perspective. A case study. Retrieved from https://www.google.gr/url?sa=t\&rct=j\&q=\&esrc $=$ s\&source=web\&cd $=1 \& c a d=r j a \& u a c t=8 \& v e d=0$ ahUKEwi 39_azuODPAhUBVRQKHVT9D9gQFggaMAA\&url=http\%3A\%2F\%2Fisites.harvard.edu\%2Ffs\%2Fdocs $\% 2$ Ficb.topic1377845.files\%2FCase_Study\%2520-\%2520Shatha\%2520and\%2520Mary.docx\&usg=AFQjC NHyKON5z1MGQN1Lqklv9Kfa5bBCMg\&sig2=42qLbP1Cvdt94DdtfgmSKA

American Management Association (AMA). (2012). Critical Skills Survey. New York. Retrieved from https://www.holynamestpa.org/uploaded/h_about_AHN/2012-Critical-Skills-Survey.pdf

Bell, J. (1999). Methodological Design. Education and Social Research. Guide for students and doctoral candidates. Athens: Gutenberg.

Bush, T. (2011). Theories of Educational Leadership and Management (4th ed.). London: Sage Publications Inc.

Dede, C. (2009). Comparing Frameworks for "21st Century Skills". Harvard Graduate School of Education. Retrieved from http://www.watertown.k12.ma.us/dept/ed_tech/research/pdf/ChrisDede.pdf

Everard, K. B., \& Morris, G. (1999). Effective Educational Management. Patras: Greek Open University.

Fokiali, P., \& Raptis, N. (2008). The training needs of teachers in primary education. Research approach. Thessaloniki: Kyriakidis Bros Publishing House S.A.

Fullan, M. (2017). Indelible Leadership. Always Leave Them Learning. Thousand Oaks, CA: Corwin.

Harris, A. (2014). Distributed Leadership Matters: Perspectives, Practicalities, and Potential. Thousand Oaks, CA: SAGE.

Harris, A., \& Jones, M. (2016). Leading Futures: Global Perspectives on Educational Leadership. Thousand Oaks, CA: SAGE.

Katsaros, J. (2008). Organization and Management of Education. Athens: Pedagogical Institute.

OECD. (2008). Improving School Leadership Project. Paris.

Pasiardis, P. (2004). Educational Leadership. From the period of the benign indifference in modern times. Athens: Routledge.

Raptis, N., \& Vitsilaki, C. (2007). Leadership and Administration of Educational Units. The identity of the director of elementary education. Thessaloniki: Kyriakidis Bros Publishing House S.A.

Reimers, F. M., \& Chung, C. K. (2016). Teaching and Learning for the Twenty-First Century. Educational goals, policies and curricula from six nations. USA: Harvard Education Press.

Saitis, C. (2007). The School Head of Modern School. From theory to practice. Athens.

Saitis, C. (2008a). Organization and Administration of Education. Athens.

Saitis, C. (2008b). The School Head of Public School. Athens: Ministry of Education -Paidagogical Institute.

Saitis, C. (2014). Initiation of teachers into the secrets of school leadership. Current trends and practices. Athens.

Soulé, H., Bates, K., \& Whitsett, J. (2013). Partnership for 21st Century Skills (P21). Wisconsin State Education Convention. Retrieved from http://wasb.org/websites/convention/File/2013/session_handouts/thursday/THURS_SSN_383_Exemplary_ 21st_Century_Learning_1015-1115AM_03.pdf

Stamatis, P. J. (2012). Communication in Educational and Administrative Process. Athens: Diadrassi Publications.

Stamatis, P. J. (2013). Communication in Education. Athens: Diadrassi Publications.

Stamatis, P. J. (2015). Preschool and Early Primary School Pedagogy. Communicative dimensions of educational process. Athens: Diadrassi Publications. 
Wiemann, J. M. (1977). Explication and test of a model of communicative competence. Human Communication Research, 3(3), 195-213.

Willke, H. (1997). Introduction to Systems Theory. N. Lips: GR Translation. Athens: Critici Publications.

\section{Notes}

Note 1.

Retrieved May 28, 2016 from

http://facweb.northseattle.edu/jreis/cmn125/communication_competence_scale.htm

Note 2. J. M. Wiemann's CV at

http://comm.ucsb.edu/sites/secure.lsit.ucsb.edu.comm.d7-3/files/people/cv/cv-wiemann.pdf.

\section{Copyrights}

Copyright for this article is retained by the author(s), with first publication rights granted to the journal.

This is an open-access article distributed under the terms and conditions of the Creative Commons Attribution license (http://creativecommons.org/licenses/by/4.0/). 